ISSN $0717-2877$

Universidad de Talca - Facultad de Ciencias Jurídicas y Sociales

Del principio de planeación en la contratación estatal: Un análisis teórico y fáctico en el orden jurídico colombiano John Fernando Restrepo Tamayo

Guillermo León Betancur Hincapié

Trabajo recibido el 11 de febrero de 2019 y aprobado el 22 de octubre de 2019

\title{
Del principio de planeación en la contratación estatal: Un análisis teórico y fáctico en el orden jurídico colombiano*
}

\section{ON THE PRINCIPLE OF PLANNING IN PUBLIC CONTRACTING: A THEORETICAL AND FACTUAL ANALYSIS IN THE COLOMBIAN} LEGAL ORDER

\author{
JOHN FERNANDO RESTREPO TAMAYO** \\ GUILLERMO LEÓN BETANCUR HINCAPIÉ***
}

\begin{abstract}
RESUMEN
El presente trabajo se traza dos objetivos: (i) mostrar de qué manera el paradigma constitucional y principialista de nuestro ordenamiento jurídico condiciona de manera fehaciente todo el andamiaje de la contratación pública y, (ii) demostrar, mediante un análisis teórico y fáctico, como el principio de planeación, sin que le medie una declaración explícita en ley, sí es un criterio esencial para desarrollar todos los demás principios, valores, deberes y funciones de la contratación pública en Colombia.
\end{abstract}

\section{ABSTRACT ${ }^{* * * *}$}

The present work has two objectives: (i) to illustrate how the constitutional and principlistic paradigm of our legal system reliably conditions the entire scaffolding of public contracting and, (ii) to demonstrate, by means of a theoretical and factual analysis, how the principle of planning, without the mediation an explicit declaration in law, whether or not it is an essential criterion to develop all other principles, values, duties and functions of public contracting in Colombia.

PALABRAS CLAVE

Paradigma constitucional, principios, planeación.

\footnotetext{
* Este artículo es resultado del trabajo académico que se adelanta en la Línea de Estado, Democracia y Constitución del Grupo de Investigación en Conflicto y Paz de la Facultad de Ciencias Sociales y Humanas de la Universidad de Medellín y se deriva del proyecto de investigación titulado: La participación ciudadana en el proceso constituyente de 1990 en Colombia. De igual manera, todo el cuerpo normativo sobre contratación público obedece a al trabajo realizado por el Grupo de Investigación Auditorio Constitucional de la Facultad de Ciencias Jurídicas y Políticas de la Institución Universitaria de Envigado.

En este proyecto de investigación, el estudiante Esteban Rodríguez Sánchez, del programa de Ciencia Política de la Universidad de Medellín participó como auxiliar de investigación.

** Abogado (Universidad de Antioquia). Politólogo (Universidad Nacional). Magíster en Filosofía (Universidad de Antioquia). Doctor en Derecho (Universidad de Medellín). Profesor de Teoría del Estado y de Derecho Constitucional. Decano de la Facultad de Ciencias Sociales y Humanas de la Universidad de Medellín, Medellín, Colombia. Correo electrónico: jfrestrepo@udem.edu.co.

*** Abogado, Especialista en Contratación Estatal, Responsabilidad Estatal y Derecho Administrativo Laboral (Institución Universitaria de Envigado). Especialista en Administración de la Informática Educativa (Universidad de Santander). Magíster en Derecho (Universidad de Medellín). Docente de Derecho Constitucional y Contratación Estatal e investigador adscrito al Grupo de Investigación Auditorio Constitucional de la Facultad de Ciencias Jurídicas y Políticas de la IUE, Envigado, Colombia, gbetancur@iue.edu.co.

**** Traducción elaborada por Rubén Darío Palacio Mesa. Licenciado en Educación Básica con Énfasis en Humanidades, Lengua Castellana e Idioma Extranjero (inglés), Magíster en Procesos de Aprendizaje y Enseñanza de Segundas Lenguas (Universidad Pontificia Bolivariana). Investigador de la Facultad de Ciencias Sociales y Humanas y Líder de la unidad de traducción del Centro de Idiomas de la Universidad de Medellín, Colombia, rupalacio@udem.edu.co.
} 
KEY WORDS

Constitutional paradigm, principles, planning.

\section{Introducción}

La Constitución colombiana de 1991 es una norma jurídica de primer nivel dentro de nuestro sistema normativo. Ello significa una modificación sustancial en el sistema de fuentes que rigen la manera de crear y concebir el derecho. La Constitución sustituye a la ley como fuente primera y se asegura, en la voz de la Corte Constitucional, la existencia de un órgano que le traduce, le unifica y le sistematiza. Con este poder, la Corte Constitucional define el contenido del modelo jurídico alrededor de condiciones básicas como la naturaleza social, la descentralización política, administrativa y territorial, la prevalencia de los derechos fundamentales y de los principios.

Sobre los principios en general, y el principio de planeación en particular, hablaremos en este texto. Nos ocuparemos de mostrar cómo hay un nuevo paradigma jurídico en el que los principios dejan de ser normas auxiliares de la actividad judicial para convertirse en criterios básicos sobre los cuales se soporta la actividad de la administración. En este caso concreto, advertimos que la contratación pública está regida por un marco de principios que dinamizan la relación entre disposiciones constitucionales y servicios públicos; entre prevalencia del interés general y garantía de derechos y oportunidades para contratistas en particular.

Si bien es cierto que la normativa que se ocupa de la contratación pública ${ }^{1}$ tiene un apartado explícito de principios, también hay lugar para señalar que dicha lista no es taxativa; sino que por el contrario, toda condición que permita justificar mayores exigencias por advertir una administración más plural, más pública, más transparente y más garante del debido proceso y la igualdad de oportunidades, mayores serán las exigencias de control sobre lo público, de recuperación en la confianza institucional y de necesidad por ampliar la esfera de condicionamiento de los principios dentro de toda la contratación pública, porque sin un uso debido de los recursos públicos por asegurar condiciones técnicas, humanas, no será posible que los interesados en tomar parte en los procesos de contratación, puedan tomar mejores decisiones sobre los temas que directamente nos afectan ${ }^{2}$ por cuanto se tramitan y se movilización con base en los recursos públicos.

Para llevar a cabo la realización de estos intereses propuestos, hemos dividido el documento en tres apartados que nos permiten comprender: (i) cuál es nuestro sistema normativo en el que los principios se conciben y se desarrollan como normas jurídicas; (ii) la naturaleza, estructura y contenido del principio de planeación y, (iii) la manera en que el principio de planeación define y condiciona el contenido de la contratación pública en Colombia.

\section{El paradigma jurídico constitucional en Colombia}

La entrada en vigencia de la Constitución Política, que tuvo lugar el 4 de julio de 1991, ha significado una modificación al sistema de fuentes en el interior del ordenamiento jurídico.

\footnotetext{
${ }^{1}$ Ley N80, de 1993.

${ }^{2}$ Constitución Política de Colombia, de 1991. Título I. De los principios fundamentales. Artículo 2.
} 
Históricamente, el modelo normativo fue heredero de las premisas legalistas que edificaron los exégetas en Francia ${ }^{3}$ y llegaron a nuestras instituciones por vía de la tradición codificada que hiciera de manera prodigiosa el jurista chileno, don Andrés Bello. Con el Código Civil y el Código Penal como referencia de comprensión del sistema normativo, se fijaron varias condiciones institucionales:

(i). El derecho queda contenido en la ley ${ }^{4}$. Esta ley es una norma jurídica esencial que se compone de dos categorías: $(a)$ supuesto fáctico $\mathrm{y},(b)$ consecuencia jurídica. Estas dos variables integran un juicio hipotético a través del cual se expresa el legislador y por medio del cual se valen los jueces, de manera definitiva, para administrar justicia. Las disposiciones legales son un atributo que tiene origen exclusivo en el legislador: órgano representativo directo de la voluntad popular.

(ii). Principios, valores, jurisprudencia, doctrina y Constitución son disposiciones de altísimo valor moral o intelectual pero que carecen de fuerza jurídica en comparación con la ley. Tienen un valor residual y un criterio auxiliar de aplicación del derecho en cuanto la ley resulta inoportuna para dirimir un caso difícil. Esto significa que tienen un rango infralegal y, por lo tanto, no sirven, por sí mismos para dirimir un conflicto de intereses en el sentido jurídico pleno. Los jueces no pueden desconocer, bajo ninguna condición una disposición legal.

(iii) Los jueces no son creadores de derecho sino meros aplicadores ${ }^{5}$. En esta dirección, la actividad judicial continúa expuesta a la posición residual que le otorgara uno de los arquitectos del modelo republicano: Montesquieu ${ }^{6}$. Para este autor, decisivo en la construcción del sistema político del mundo revolucionario francés, los jueces cumplen la función de administrar justicia ajustados al imperio de la ley. Y para hacerlo de manera objetiva, pues debe recordarse que uno de los objetivos revolucionarios era superar las prácticas despóticas del monarca guillotinado, se les exigirá ajustarse de manera taxativa a las exigencias legales. Valerse exclusivamente de imperativos categóricos a la hora de dirimir conflictos, y de esta manera, administrar justicia de manera objetiva y proveer a todo el sistema de seguridad jurídica. De tal forma que haya confianza para operadores jurídicos y asociados de que los jueces actúan según el derecho y no según sus creencias, sus pasiones, sus miedos o sus impulsos. El telos legal es la única garantía de que el gobierno de las leyes, tal como lo anunciara Aristóteles ${ }^{7}$, se imponga sobre el gobierno de los hombres.

(iv) Para este modelo normativo exegético positivo, la pregunta central reposa en la validez y no en la justicia ${ }^{8}$. Los operadores jurídicos hacen lo que la ley les autoriza. Los particulares hacen lo que la ley no les prohíbe. Ahí nace la esencia del principio de legalidad ${ }^{9}$. Una disposición legal define el alcance de lo permitido y lo prohibido. Esta disposición legal que tiene origen en el Parlamento es de vocación racional y no divina. La validez está dada por la verificación de que la ley se haya emitido por el órgano competente y según unas formalidades procedimentales exigidas en una ley anterior. Así la publicidad, la igualdad, la transparencia y el debido proceso se presentan como los atributos más destacables para defender este nuevo régimen. Sin intromisión de una autoridad, divina o sagrada, que contradiga o condiciones la voluntad del nuevo soberano.

La Constitución de 1991 de Colombia surge como consecuencia de un cambio generacional, liderado por estudiantes universitarios, que advierte la estrechez del orden jurídico legalista y constitucional decimonónico; la timidez de los intelectuales; la vocación autodestructiva de la izquierda armada; la indiferencia de los empresarios; la maldad de los narcotraficantes y la

\footnotetext{
${ }^{3}$ LÓPEZ (2008), p. 2.

${ }^{4}$ CAPELLA (2008), p. 128.

${ }^{5}$ LÓPEZ (2006), p. 4.

${ }^{6}$ MONTESQUIEU (2007), p. 183.

${ }^{7}$ ARISTÓTELES (2008), p. 107.

${ }^{8}$ BASTIDA (2001), p. 40.

${ }^{9}$ ÁLVAREZ (2010), p. 27.
} 
incapacidad moral e intelectual de la clase política de turno para recuperar la institucionalidad y la decencia ${ }^{10}$. El mundo avisaba tiempos de transformación, pero poco o nada, resultaba útil. El Palacio de Justicia en llamas, las víctimas bajo el lodo del volcán, ministros, policías, jueces, fiscales y candidatos presidencial asesinados fueron hechos que exigían una repuesta de estructura y no de superficie ${ }^{11}$. Esfuerzo que requería la sabiduría de Apolo y la entrega de Aquiles. Y los estudiantes lo fueron. Fusionaron fuerza y pasión; entrega y compromiso y lograron mover el timón que empezó con una papeleta y terminó en la instalación de una asamblea nacional constituyente ${ }^{12}$.

En cumplimiento del plazo estipulado; entre el 5 de febrero y el 4 de julio de 1991, 72 delegados con sus equipos de trabajo se dieron la tarea de redactar una hoja de ruta que fijara nuevas reglas de juego sobre la manera de entender el poder público, sus instituciones y sus principios ${ }^{13}$. De la puesta en práctica de esta Norma primera se ha estructura una nueva manera de concebir el orden jurídico. A continuación, señalaremos las principales características:

(i). Constitución como norma jurídica primera. La Constitución empieza a ser concebida como una norma jurídica. Reza el artículo 4 Superior: "La Constitución es norma de normas"14. Aquí ya hay una gran diferencia con el orden jurídico francés, en el que la Ley era la norma jurídica primera y la Constitución se concebía más como un conjunto de enunciados de filosofía política, que, si bien podía describir los valores de una época de transición del absolutismo a la república, no aplicaba como criterio exclusivo de decisión jurídica. Siguiendo la propuesta trazada por la Suprema Corte de los Estados Unidos ${ }^{15}$ y Hans Kelsen ${ }^{16}$, se acepta que la Constitución es una norma de estricta creación jurídica y no existe una norma jurídica superior que le condicione. La Constitución es la norma jurídica con la que empieza el orden jurídico y la ley, los contratos, las sentencias y los actos administrativos, son normas jurídicas supeditadas a las disposiciones formales y materiales que contiene la Constitución ${ }^{17}$.

(ii). Corte Constitucional como máximo intérprete. Una vez más, siguiendo a Kelsen se establece que debe ser un órgano de naturaleza judicial, alejado de los intereses políticos que circundan al ejecutivo y al legislativo, el encargado de verificar que toda norma que ingresa al orden jurídico, guarde una correspondencia formal y material con las disposiciones constitucionales. Aquí empieza a tejerse una estrecha relación entre los presupuestos básicos del modelo normativo constitucional, por cuanto la actuación de la Corte Constitucional, a la hora de realizar la revisión de las normas a la luz de disposiciones constitucional está asegurando la continuidad de la vigencia de la Constitución como norma jurídica del orden positivo. Pero, además, la Corte Constitucional no solo goza de la facultad normativa para anular normas que considere, sean contrarias a la Constitución (en los términos de legislador negativo) sino que además goza de la competencia y necesidad fáctica de generar unidad interpretativa sobre el orden jurídico en general ${ }^{18}$.

El origen democrático, representativo y plural de la Constitución también acarrea el riesgo de que exista en su interior una serie de fisuras que el mundo de la vida pone en evidencia y generar como consecuencia que una norma puede resultar de manera simultánea ajustada y contraria a la Constitución. ¿Qué hace entonces la Corte Constitucional? Dirimir conflictos de interpretación entre

\footnotetext{
${ }^{10}$ LONDOÑO (2015), p. 28.

${ }^{11}$ RESTREPO (2013).

${ }^{12}$ LEMAITRE (2016), p. 56.

${ }^{13}$ OLANO (2007), p. 321.

${ }^{14}$ Constitución Política de Colombia, 1991. Título I. De los principios fundamentales. Artículo 4.

${ }^{15}$ U.S Supreme Court. Marbury vs Madison, 5 U.S 137, (1803).

${ }^{16}$ KELSEN (2009).

17 KELSEN (2009), p. 113.

${ }^{18}$ RESTREPO (2018), p. 166.
} 
normas; verificar que exista unidad de comprensión sobre el alcance y el contenido de decisiones políticas, religiosas, culturales o morales a la luz de los presupuestos básicos de comprensión del orden jurídico constitucional que se contiene en principios (autodeterminación, dignidad y supervivencia), valores (participación, representación y orden justo) y derechos fundamentales (vida, dignidad, libertad, igualdad y debido proceso) ${ }^{19}$.

(iii) Democracia corregida. Significa que las decisiones políticas, por tener lugar en un régimen democrático, están sujetas a la voluntad de las mayorías. Pero tal voluntad no es ilimitada. La democracia corregida significa el límite que los principios, los valores y los derechos fundamentales trazan en favor de las minorías. Es decir, aquellas demandas individuales o ciudadanas que no generan réditos electorales; pero que al tener conexidad con un principio o con un valor constitucional, sirve como un freno, que la Corte Constitucional reconoce, a un régimen político, que en nombre de la Voluntad general usurpe o extralimite el alcance y el contenido de sus funciones ${ }^{20}$.

(iv) Liberalismo corregido. Significa que mediante la declaratoria de Estado social de derecho se instala una síntesis entre principios liberales de respeto extremo por las libertades individuales y responsabilidad estatal de intervenir en la economía con el ánimo de corregir, mediante asistencia material y subsidios, la distancia social, cultural, política y económica que tiene lugar entre la élite y los menos aventajados ${ }^{21}$. Liberalismo corregido no es socialismo por cuanto se conserva la defensa de la propiedad privada pero sí exige que las demandas ciudadanas de asistencia sean el punto de partida de una política pública o a que la lista de derechos de intervención como la salud, la cultura, la educación, la vivienda o el medio ambienta dejen de ser derechos de carácter prestacional que se satisfacen según condiciones de pago para convertirse en derechos fundamentales de aplicación inmediata y de protección directa mediante acción de tutela (Sentencia T-227 de 2003) ${ }^{22}$.

\section{De los principios en el orden jurídico}

Un principio es una máxima moral y ética con vocación de universalidad cuya proposición se ajusta a un mandato racional y razonable que define una condición del obrar correctamente. Es el presupuesto filosófico de todo orden jurídico (natural, legal, realista, positivista, socialista y constitucional) que se concibe sobre la pretensión de asegurar una vida buena para todos los asociados y se define según la vocación de lo justo. Aunque sea precisamente dicha máxima de justicia la que mude según el régimen ideológico que esté en el poder. La justicia puede oscilar entre el perdón y el castigo. Entre la retribución o la restauración. En cada extremo del péndulo siempre habrá un soporte deontológico sobre el cual se insertan y se estructuran los principios. Su textura es abierta y su naturaleza, moral o jurídica, determina el papel que ocupa en el interior del orden jurídico.

Para los iusnaturalistas ${ }^{23}$, los principios son máximas universales, derivadas de una autoridad superior o expresión de un orden racional que define, condiciona y determina la esfera de validez de las normas positivas ${ }^{24}$. Los principios no aparecen explícitamente positivizados en el orden jurídico, pero dada su categoría superior de bondad razonable lo hace innecesario. Son

\footnotetext{
${ }^{19}$ BERNAL (2006), pp. 245-257.

${ }^{20}$ FERRAJOLI (2014), p. 37.

${ }^{21}$ RAWLS (2003), pp. 35-36.

${ }^{22}$ Corte Constitucional, Sentencia $\mathrm{N}^{\circ} \mathrm{T}-227$ de 2003, de 17 de marzo de 2003.

${ }^{23}$ RADBRUCH (2010), pp. 178-180.

${ }^{24}$ SÓFOCLES (2014), pp. 77-78.
} 
públicamente conocidos, prolongados en el tiempo y se perpetúan entre generaciones. Para los exégetas, los principios son máximas morales de naturaleza teológica que no tienen lugar en el mundo jurídico. No son criterio de validez ni definen el contenido de una pretensión jurídica. Son disposiciones éticas que se circunscriben a la esfera más íntima del sujeto y carecen de rango jurídico. La esfera jurídica solo tiene sentido en dirección legal, expresada en juicios hipotéticos. Aquí es donde la textura abierta de los principios representa una decidida necesidad de exclusión porque la apertura gramatical puede verterse de sesgos ideológicos, políticos o morales a los que el operador jurídico no tiene acceso.

Para John Rawls ${ }^{25}$, los dos principios de justicia sobre los cuales se soporta el cimiento institucional y orgánico de una sociedad plural, ordenada y justa, definen los términos equitativos de cooperación entre ciudadanos que se conciben a sí mismos, y entre sí, como libres e iguales. Estos dos principios son la esencia de la justicia entendida como equidad. Se proponen como criterios de orientación para que las instituciones básicas hagan posible la realización de los valores de libertad e igualdad. Estos dos principios de justicia son: Principio 1:

Todas las personas son iguales en punto a exigir un esquema adecuado de derechos y libertades básicos iguales, esquema que es compatible con el mismo esquema para todos; y en ese esquema se garantiza su valor equitativo solo a iguales libertades políticas.

\section{Principio 2:}

Las desigualdades sociales y económicas tienen que satisfacer dos condiciones: $(a)$ deben andar vinculadas a posiciones y cargos abiertos a todos en condiciones de igualdad equitativa de oportunidades $y,(b)$ deben promover el mayor beneficio para los menos aventajados de la sociedad.

Los dos principios de justicia son la expresión del contenido de una concepción política liberal de justicia. Dicho contenido está dado por tres características básicas: (i) definen derechos y libertades propios de un régimen democrático constitucional; (ii) confieren a tales derechos una esfera especial de mayor protección y, (iii) exigen medidas efectivas de protección para que todos los asociados puedan hacer un uso efectivo de libertades y oportunidades.

Para Ronald Dworkin ${ }^{26}$, en su voraz esfuerzo por dinamitar los pilares del positivismo hartiano, los principios no son normas sino una fuente válida y legítima sobre la cual reposa la decisión judicial para dirimir un conflicto (caso difícil), que puede llevar incluso a la inaplicación de una norma, sobre la que el positivismo ha puesto su entera confianza y comprensión del derecho. Afirma Dworkin que una norma del orden sucesoral no puede aplicarse si el heredero ha sido quien ha dado muerte a su padre con el ánimo de recibir la herencia. En atención a la norma (derecho positivo válido y exigible) el único sobreviviente es quien merece recibir la herencia, pero esta máxima no puede tener lugar porque a esa norma se le opone, de manera vencedora, un principio de justicia que establece que a nadie puede permitírsele que se aproveche de su propio fraude. Dice Dworkin:

Llamo principio a un estándar que ha de ser observado, no porque favorezca o asegure una situación económica, política o social que se considera deseable, sino porque es una exigencia de la justicia, la equidad o alguna otra dimensión de la moralidad.

\footnotetext{
${ }^{25}$ RAWLS (2003), pp. 35-36.

${ }^{26}$ DWORKIN (1995), pp. 72-80.
} 
Para Robert Alexy ${ }^{27}$, un orden jurídico puede basarse tanto en reglas como en principios. Las reglas son mandatos definitivos. Su realización se mide en términos de todo o nada. Los principios son mandatos de optimización. Y aquí radica su principal diferencia entre unas y otros. Un mandato de optimización significa que son normas que ordenan que algo se realice en mayor o menor medida. Su realización y perfeccionamiento resultan condicionados por posibilidades fácticas y jurídicas. Por este criterio de optimización resulta evidente que el relacionamiento de las reglas está dado por condiciones de exclusión. Un ordenamiento jurídico no puede aceptar que sean vigentes dos normas que se anulan entre sí. Lo que una regla permite, otra no puede prohibirlo. En cambio, el relacionamiento de los principios está dado por condiciones de ponderación; esto es, la preferencia según condiciones de razonabilidad, sensatez y pertinencia que, en un caso concreto, permite establecer que un principio pesa más que otro, sin que ello signifique que el principio vencido en la ponderación sea excluido del orden jurídico.

Para García de Enterría ${ }^{28}$, los principios describen y contienen la carga axiológica a través de la cual la Constitución define la unidad del orden jurídico. Los principios son una explícita declaración constitucional que ostentan un valor jurídico superior al de "simples reglas formales de producción de normas". Expresan la voluntad suprema de una comunidad que por medio de su Constitución instala unos valores sociales básicos, propios y primordiales para la vida común. Esta conjugación de valores no es simple retórica de falaz doctrina de fuerza inercial. Son la base entera del orden jurídico, que ha de llenarlo de un sentido propio, definitivo y diferenciador. Presiden, necesariamente, toda la esfera de interpretación y de aplicación del orden jurídico.

Para Estrada ${ }^{29}$, los principios son normas jurídicas. Expresión fidedigna de la voluntad del constituyente primario, en ejercicio de su poder soberano. Se insertan positivamente al orden jurídico por medio de la doctrina y la jurisprudencia. Ostentan una naturaleza axiológica que permite completar y desarrollar enunciados constitucionales, tanto en sentido formal como material.

Para Ferrajoli ${ }^{30}$ en el interior de un modelo jurídico constitucional o neo-positivista, los principios, al igual que los derechos fundamentales, son criterios básicos de validez de las demás normas que integran el orden jurídico. Tienen un rango jurídico supra-legal porque su linaje se deriva explícitamente de la Constitución.

En el interior del sistema normativo constitucional colombiano los principios son normas jurídicas, que, a pesar de tener una textura abierta, definen el horizonte hermenéutico y comprensivo del derecho. Permiten fundar tanto una pretensión como una decisión en estricto sentido jurídico. Su naturaleza es jurídica porque su existencia, uso, aplicación y comprensión tienen soporte constitucional, de tal forma que ocupan un lugar supra-legal en el interior del orden jurídico. Definen el horizonte dogmático del Estado y soportan las condiciones fácticas de los derechos fundamentales ${ }^{31}$. La presencia de los principios en el interior del orden jurídico es sumamente amplia. A continuación, se enuncian algunos ejemplos:

Estado social de derecho, estructura unitaria, descentralización y dignidad (Artículo 1 Superior) ${ }^{32}$; soberanía popular constitucionalizada (Artículo 3 Superior) ${ }^{33}$; supremacía de la

\footnotetext{
${ }^{27}$ ALEXY (1994), p. 162.

${ }^{28}$ GARCÍA DE ENTERRÍA (2001), pp. 97-99.

${ }^{29}$ ESTRADA (2007), p. 46.

${ }^{30}$ FERRAJOLI (2014), p. 19.

${ }^{31}$ RESTREPO (2018), p. 59. Todo derecho fundamental reposa sobre la salvaguarda y realización de al menos uno de estos tres principios: dignidad, supervivencia y autodeterminación.

${ }^{32}$ Constitución Política de Colombia, de 1991. Título I. De los principios fundamentales. Artículo 1.

${ }^{33}$ Constitución Política de Colombia, de 1991. Título I. De los principios fundamentales. Artículo 3.
} 
Constitución (Artículo 4 Superior) ${ }^{34}$; Estado pluri-étnico y pluri-cultural (Artículo 7 Superior) ${ }^{35}$; eficiencia, universalidad y progresividad como principios rectores de la seguridad social (Artículo 48 Superior) $^{36}$; Bloque de constitucionalidad en sentido estricto (Artículo 93 Superior) ${ }^{37}$; Bloque de constitucionalidad en sentido lato y adopción de derechos fundamentales innominados (Artículo 94 Superior) ${ }^{38}$; legalidad (Artículo 121 Superior) ${ }^{39}$; igualdad, moralidad, eficacia, economía, celeridad, imparcialidad y publicidad como principios rectores de la función administrativa (Artículo 209 Superior) ${ }^{40}$; transparencia, economía y responsabilidad como principios rectores de la contratación pública (Ley 80 de 1993) ${ }^{41}$; debido proceso, igualdad, imparcialidad, buena fe, moralidad, participación, responsabilidad, transparencia, publicidad, coordinación, planeación, eficacia, economía y celeridad como principios rectores del Código Procesal Administrativo y de lo Contencioso Administrativo (Ley 1437 de 2011)42; principio del mínimo vital (Sentencia T-518A de $2011)^{43} y$, progresividad (Sentencia C-492 de 2015) ${ }^{44}$.

\section{La instalación de los principios en la contratación pública}

Como bien se colige del Estatuto General de Contratación de la Administración Pública, consagrado en la Ley 80 de 1993, modificado y complementado por la Ley 1150 de 2007, y reglamentado por el Decreto 1082 de 2015, dicho estatuto contractual es, sin lugar a dudas, un estatuto de principios ${ }^{45}$. Tal afirmación, que ya había sido advertida por la doctrina especializada en materia de contratación estatal ${ }^{46}$, se infiere directamente desde la misma exposición de motivos que antecedió a la expedición de la Ley 80 de 1993, texto en el cual se expuso que dicho estatuto contractual estaría en consonancia con los principios que constitucionalmente rigen la función administrativa ${ }^{47}$, y se estructuraría además, "sobre principios generales a los cuales deben sujetarse las entidades públicas y los contratistas en su actuar contractual”48.

De manera consecuente con la exposición de motivos, la Ley 80 de 1993, al referirse expresamente a su objeto, señaló en su artículo 1 que "la presente ley tiene por objeto disponer las reglas y principios que rigen los contratos de las entidades estatales" ${ }^{\prime 9}$. Y, en la misma orientación, el artículo 23, al hacer alusión a los principios que deben regir las actuaciones contractuales de las entidades estatales dispuso:

"Las actuaciones de quienes intervengan en la contratación estatal se desarrollarán con arreglo a los principios de transparencia, economía y responsabilidad y de conformidad con los postulados que rigen la función administrativa. Igualmente, se aplicarán en las mismas las normas

\footnotetext{
${ }^{34}$ Constitución Política de Colombia, de 1991. Título I. De los principios fundamentales. Artículo 4.

${ }^{35}$ Constitución Política de Colombia, de 1991. Título I. De los principios fundamentales. Artículo 7.

${ }^{36}$ Constitución Política de Colombia, de 1991. Título II. De los derechos, las garantías y los deberes. Artículo 48.

${ }^{37}$ Constitución Política de Colombia, de 1991. Título II. De los derechos, las garantías y los deberes. Artículo 93.

${ }^{38}$ Constitución Política de Colombia, de 1991. Título II. De los derechos, las garantías y los deberes. Artículo 94.

${ }^{39}$ Constitución Política de Colombia, de 1991. Título I. De los principios fundamentales. Artículo 121.

${ }^{40}$ Constitución Política de Colombia, de 1991. Título VII. De la rama ejecutiva. Artículo 209.

${ }^{41}$ Ley $\mathrm{N}^{\circ} 80$, de 1993.

${ }^{42}$ Ley $\mathrm{N}^{\circ} 1437$, de 2011.

${ }^{43}$ Corte Constitucional, Sentencia N ${ }^{\circ}$ T-518A, de 16 de febrero de 2011.

${ }^{44}$ Corte Constitucional, Sentencia N ${ }^{\circ}$ C-492, de 5 de agosto de 2015.

${ }^{45}$ RICO (2013).

${ }^{46}$ MATALLANA (2015).

${ }^{47}$ Constitución Política de Colombia, de 1991. Título VII. De la Rama Ejecutiva Capítulo V. De la función administrativa, Artículo 209.

${ }^{48}$ CONGRESO DE LA REPÚBLICA DE COLOMBIA (1993).

${ }^{49}$ Ley N80, de 1993. Artículo 1.
} 
que regulan la conducta de los servidores públicos, las reglas de interpretación de la contratación, los principios generales del derecho y los particulares del derecho administrativo" ${ }^{50}$.

En igual sentido, y como una reiteración del carácter marcadamente principialista del estatuto de contratación pública, el artículo 24 de la Ley 80 de 1993, al desarrollar el principio de transparencia, indicó en su parágrafo 2 que: "El Gobierno Nacional expedirá, dentro de los seis (6) meses siguientes a la promulgación de esta ley, un reglamento de contratación directa, cuyas disposiciones garanticen y desarrollen los principios de economía, transparencia y selección objetiva previstos en ella" ${ }^{51}$. Tal enunciación de principios se reiteró en el parágrafo 3 del mismo artículo 24, cuando al referirse a la enajenación de bienes estatales por el sistema de martillo y a través del sistema de subasta, manifestó que:

la selección de la entidad vendedora la hará la respectiva entidad estatal, de acuerdo con los principios de transparencia, economía, responsabilidad y selección objetiva y teniendo en cuenta la capacidad administrativa que pueda emplear cada entidad financiera para realizar los remates ${ }^{52}$.

Siguiendo la misma línea trazada anteriormente en el artículo 23 del estatuto contractual de la Administración Pública al hacer mención a la interpretación de las reglas contractuales, se hizo alusión directa a la consagración de ciertos principios que deben tenerse en cuenta, tanto para la selección de los contratistas, como para la redacción de las cláusulas que se incorporen en los contratos estatales, es así, como el texto literal de la norma preceptúa que:

En la interpretación de las normas sobre contratos estatales, relativas a procedimientos de selección y escogencia de contratistas y en la de las cláusulas y estipulaciones de los contratos, se tendrán en consideración los fines y los principios de que trata esta ley, los mandatos de la buena fe y la igualdad y equilibrio entre prestaciones y derechos que caracteriza a los contratos conmutativos ${ }^{53}$.

En ese orden de ideas, de las consideraciones precedentes se demuestra que la Ley 80 de 1993, en su calidad de Estatuto General de Contratación de la Administración Pública, sí es un estatuto de principios, toda vez que en su articulado constantemente se hace alusión expresa a ellos; para constatar tal aserto, solo basta con observar los artículos 1, 20, 23, 24, 26, 27, 28, 29, 38, 40, 41, 62, 76 y 77 de la referida Ley; para corroborar que los principios, tal y como se aseveró desde la exposición de motivos de dicho cuerpo normativo, "constituyen una especie de tabla de la ley que deben asimilar los usuarios de la contratación" ${ }^{54}$; con lo cual se les concibe como una garantía para que la actividad contractual del Estado se convierta en la herramienta más eficaz para el logro de sus cometidos esenciales, y para asegurar el cumplimiento de sus deberes sociales; en síntesis, para la consecución de los fines del Estado ${ }^{55}$.

Es tan importante la observancia de los principios en el desarrollo de todo proceso contractual del Estado, incluso desde la misma etapa precontractual, que la inobservancia de los mismos se encuentra tipificada como falta disciplinaria gravísima, descrita en el numeral 31 del artículo 48 de la Ley 734 de 2002, en el que se tipifica como tal: "participar en la etapa precontractual en detrimento del patrimonio público, o con desconocimiento de los principios que

\footnotetext{
${ }^{50}$ Ley $\mathrm{N}^{\circ} 80$, de 1993. Artículo 23.

${ }^{51}$ Ley $N^{\circ} 80$, de 1993. Artículo 24. Parágrafo 2.

${ }^{52}$ Ley N ${ }^{\circ} 80$, de 1993. Artículo 24. Parágrafo 3. Inciso 2.

${ }^{53}$ Ley N 80, de 1993. Artículo 27.

${ }^{54}$ CONGRESO DE LA REPÚBLICA DE COLOMBIA (1993).

${ }^{55}$ BETANCUR (2015).
} 
regulan la contratación estatal y la función administrativa contemplados en la Constitución y en la ley" ${ }^{56}$. La citada disposición normativa ha sido aplicada reiteradamente por la Sala de lo Contencioso Administrativo del Consejo de Estado, y una muestra de ello se encuentra en reciente Fallo del 25 de enero de 2018, expediente (1358-12), en el cual se afirma de manera categórica:

Por lo tanto la escogencia del contratista cualquiera sea la forma de selección, es decir, licitación pública o contratación directa, no puede ser subjetiva, debe siempre acatar los procedimientos claramente señalados por el estatuto contractual y sus decretos reglamentarios, de suerte que, cuando se desconocen los procedimientos y principios rectores que rigen la actividad contractual, la conducta es irregular y compromete como lógica consecuencia, la responsabilidad del Jefe del organismo que celebró la contratación en esas condiciones ${ }^{57}$.

En sentido similar, la Corte Constitucional, mediante Sentencia C-508 de 2002, ya había expresado al referirse a los principios que rigen la contratación estatal, enunciados por el legislador en los artículos 23 y siguientes de la Ley 80 de 1993, que estos "no son simples definiciones legales, sino normas de contenido específico, de obligatorio acatamiento en toda la contratación estatal, sea cual fuere la modalidad en que esta se realice" ${ }^{\prime 58}$.

Ahora bien, en la misma línea discursiva, y en armonía con lo expuesto hasta esta parte, cabe preguntarse entonces, ¿cuáles son los principios a los que directa o indirectamente alude el estatuto contractual para ser aplicados en todas y cada una de las relaciones negociales del Estado? Para contestar este interrogante, es preciso advertir que si bien puede hacerse un listado enunciativo de tales principios, dicho listado corresponderá, ab initio, a aquellos principios que se mencionan expresamente en el estatuto contractual, sin que ello signifique en absoluto el desconocimiento de otros principios que sin ser mencionados expresamente como tales, se derivan del mismo estatuto contractual, para lo cual, y en orden a los fines de nuestros argumentos, algunos de ellos se enunciarán a título meramente informativo en el presente análisis.

Así, auscultado el contenido de la Ley 80 de 1993, se tienen como principios aplicables a todas las relaciones contractuales estatales, y, por consiguiente, de obligatorio cumplimiento para todos sus partícipes, entre otros los siguientes: prevalencia del interés público ${ }^{59}$; reciprocidad ${ }^{60}$; transparencia ${ }^{61}$; economía; planeación; debido proceso $^{62}$; responsabilidad $^{63}$; equilibrio contractual $^{64}$; buena fe; igualdad ${ }^{65}$; y selección objetiva ${ }^{66}$.

Adicionalmente, por remisión del mismo artículo 23 de la Ley 80 de 1993, han de considerarse los principios generales del derecho, dentro de los cuales se abre una importante gama de postulados básicos cuya aplicación no puede ser desconocida en las relaciones contractuales del Estado, pues adquieren especial significación, especialmente al momento de resolver situaciones ante las cuales no se encuentra norma aplicable al caso concreto, como puede ocurrir con principios tales como la confianza legítima, el no enriquecimiento sin causa, el no abuso del derecho, y la

\footnotetext{
${ }^{56}$ Ley N ${ }^{\circ} 734$, de 2002. Artículo 48. Numeral 31.

${ }^{57}$ Consejo de Estado, Expediente $\mathrm{N}^{\circ} 1358-12$, de 25 de enero de 2018.

${ }^{58}$ Corte Constitucional, Sentencia $\mathrm{N}^{\circ} \mathrm{C}-508$, de 3 de julio de 2002.

${ }^{59}$ Ley $\mathrm{N}^{\circ} 80$, de 1993. Artículo 3.

${ }^{60}$ Ley Nº 80, de 1993. Artículo 20.

${ }^{61}$ Ley $\mathrm{N}^{\circ} 80$, de 1993. Artículo 24.

${ }^{62}$ Ley N ${ }^{\circ} 80$, de 1993. Artículo 25.

${ }^{63}$ Ley $\mathrm{N}^{\circ} 80$, de 1993. Artículo 26.

${ }^{64}$ Ley $\mathrm{N}^{\circ} 80$, de 1993. Artículo 27.

${ }^{65}$ Ley N ${ }^{\circ} 80$, de 1993. Artículo 28.

${ }^{66}$ Ley N 80 , de 1993. Artículo 29.
} 
primacía de la realidad sobre las meras formas, entre otros. Todo lo anterior, sin detrimento de los preceptos constitucionales consagrados en el preámbulo de la Constitución Política y de los principios fundamentales establecidos en sus dos primeros artículos ${ }^{67}$.

No cabe duda entonces que las relaciones contractuales del Estado están necesariamente transversalizadas por toda una pléyade de principios, algunos de raigambre constitucional como aquellos que rigen la función administrativa, e incluso los propios de la gestión fiscal (eficiencia, economía, equidad y valoración de los costos ambientales); y otros de origen legal, como los que caracterizan la contratación estatal, incluidos en la Ley 80 de 1993, y aquellos propios del derecho administrativo, señalados en el artículo $3^{\circ}$ de la Ley 1437 de $2011^{68}$. Tales postulados fundamentales, amén de los contemplados en la legislación civil y comercial, constituyen "un cuerpo interpretativo, integrador y creador para la contratación estatal, al cual se someten por igual, particulares y entidades estatales" 69 .

En orden al propósito del presente discurrir académico, de iniciar un sucinto análisis de tipo enunciativo, descriptivo y analítico de los principios aplicables en la contratación estatal, se procederá a continuación al desglose del primero y más importante de ellos, el principio de planeación, exponiendo de contera su conceptualización y notas caracterizadoras elementales; finalidad que habrá de soportarse con apoyo en la doctrina y la jurisprudencia especializada en la materia, partiendo del aserto según el cual la planeación es el eje fundamental sobre el que se desarrolla el proceso de contratación de obras, y la adquisición de bienes y servicios por parte de las entidades estatales.

\section{Del principio de planeación}

Afirma la Corte Constitucional que el principio de planeación debe entenderse, en el marco de la contratación pública, como aquella exigencia que recae sobre la entidad pública de asegurar la veraz y amplia realización de estudios técnicos previos adecuados, de tal manera que resulte posible, fiable y público que la entidad defina con total certeza el objeto y naturaleza del contrato, las obligaciones que se generan, la distribución de riesgos y el precio. De tal manera que se les asegure a todos los asociados interesados en tomar parte del proceso contractual saber sus alcances, límites y posibilidades de financiación y de perfeccionamiento del contrato propuesto. El principio de planeación va de la mano de la realización de otros principios decisivos como la publicidad, la economía y el debido proceso (Sentencia C-300 de 2012) ${ }^{70}$.

Este principio, no obstante no estar tipificado expresamente en el Estatuto General de Contratación de la Administración Pública, se deriva de lo preceptuado en sus artículos 4, 5; en los numerales 6, 7, 12, 13 y 14 del artículo 25; en el \# 3 del artículo 26; en los numerales 1 y 2 del artículo 30; además, de los artículos 4, 5 y 6 de la Ley 1150 de 2007; del artículo 4 de la Ley 1508 de 2012; de los artículos 2.2.1.1.1.6.1 a 2.2.1.1.1.6.3 del Decreto 1082 de 2015, y de lo dispuesto en la Subsección 1 de la Sección 2 del mismo decreto.

El principio de planeación tiene fundamento y se infiere de los artículos 209, 339 y 341 constitucionales, e implica que el negocio jurídico contractual deberá estar debidamente diseñado y pensado conforme a las necesidades y prioridades que demande el interés público, dirigido al aseguramiento de la eficacia de la actividad contractual estatal, a la efectiva satisfacción del interés

\footnotetext{
${ }^{67}$ CONSEJO DE ESTADO, Expediente $N^{\circ} 49.847$, de 27 de enero de 2016.

${ }^{68}$ BETANCUR (2015).

${ }^{69}$ RICO (2013), p. 318

${ }^{70}$ CORTE CONSTITUCIONAL, Sentencia N ${ }^{\circ}$ C-300, de 25 de abril de 2012.
} 
general, y a la protección del patrimonio público, aspectos que subyacen involucrados en todo contrato estatal, cuyo trasunto está en la continua y eficiente prestación de los servicios públicos y en la efectividad de los derechos e intereses de los administrados. De ahí que, según la reiterada jurisprudencia del Consejo de Estado, la ausencia de dicho principio ataca directamente la esencia misma del interés público, generando consecuencias nefastas no solo para el logro del objeto contractual, sino también para el interés general y para el patrimonio público ${ }^{71}$.

La planeación como principio fundamental de la contratación administrativa, implica que el mismo se encuentra inescindiblemente ligado a la viabilidad financiera del contrato estatal ${ }^{72}$; y ello es así, en la medida en que, en consonancia con el principio de economía, el numeral 13 del artículo 25 de la Ley 80 de 1993, ordena a las autoridades constituir previamente las reservas y compromisos presupuestales necesarios, teniendo como base el valor de las prestaciones al momento de la celebración del contrato, y el estimativo de los ajustes resultantes en caso de aplicarse la actualización de precios.

Asimismo, en el numeral 14 del mismo artículo, se da la instrucción precisa para que en los presupuestos anuales se incluya una apropiación global destinada al cubrimiento de los costos imprevistos que puedan tener lugar como consecuencia del retardo en los pagos o al aplicar la revisión de los precios cuando las condiciones pactadas inicialmente sufran alteraciones ${ }^{73}$.

Como soporte jurisprudencial de las ideas que se han venido aseverando, el Consejo de Estado, a través de su Sala Plena de lo Contencioso Administrativo, Sección Tercera, en providencia del 28 de mayo de 2012, ha manifestado lo siguiente:

El deber de planeación, en tanto manifestación del principio de economía, tiene por finalidad asegurar que todo proyecto esté precedido de los estudios de orden técnico, financiero y jurídico requeridos para determinar su viabilidad económica y técnica y así poder establecer la conveniencia o no del objeto por contratar; si resulta o no necesario celebrar el respectivo negocio jurídico y su adecuación a los planes de inversión, de adquisición o compras, presupuesto y ley de apropiaciones, según el caso; y de ser necesario, deberá estar acompañado, además, de los diseños, planos y evaluaciones de prefactibilidad o factibilidad; qué modalidades contractuales pueden utilizarse y cuál de ellas resulta ser la más aconsejable; las características que deba reunir el bien o servicio objeto de licitación; así como los costos y recursos que su celebración y ejecución demanden ${ }^{74}$.

El principio de planeación está indisolublemente anclado a la proyección económica, financiera y presupuestal, es por ello que la entidad estatal debe contar previamente con las respectivas apropiaciones presupuestales, siendo necesario establecer si el pago de las obligaciones derivadas del contrato será asumido en la respectiva vigencia fiscal, o si por el contrario, se deberá tramitar la autorización de compromiso de vigencias futuras de conformidad con lo indicado en el Estatuto Orgánico de Presupuesto y en las demás normas concordantes ${ }^{75}$.

Esta correlación necesaria entre los principios de planeación y de economía, encuentra su punto normativo más alto en el numeral 12 del mismo artículo 25 de la Ley 80 de 1993, norma que fue modificada por el artículo 87 de la Ley 1474 de 2011, y que preceptúa que

\footnotetext{
${ }^{71}$ Consejo de Estado, Expediente N51489, de 10 de diciembre de 2015.

72 RODRÍGUEZ (2013).

${ }^{73}$ Ley N ${ }^{\circ} 80$, de 1993. Artículo 25, numerales 13-14.

${ }^{74}$ Consejo de Estado, Expediente $N^{\circ} 21489$, de 28 de mayo de 2012.

${ }^{75}$ BETANCUR (2015).
} 
previo a la apertura de un proceso de licitación o la firma del contrato en caso de que la modalidad de selección sea contratación directa, deberán elaborarse los estudios, diseños y proyectos requeridos, y los pliegos de condiciones según corresponda ${ }^{76}$.

Partiendo de la normativa citada, puede afirmarse que con fundamento en el principio de planeación, la entidad estatal, una vez identificada la necesidad que se pretende satisfacer, lo cual debe preverse desde la elaboración del Plan Anual de Adquisiciones, y en procura de atender de manera oportuna y eficiente dicho requerimiento, debe definir, delinear y delimitar, no solo el objeto contractual, sino también los pasos a seguir para el logro efectivo de dicho objeto, estableciendo los procedimientos que se surtirán en cada una de las fases de la futura contratación, poniendo especial énfasis en las etapas preparatoria y precontractual, pues es allí precisamente en donde radican la solidez y la estructura de todo proceso contractual.

Insiste la doctrina en que es primordial y específicamente en la fase precontractual que la Administración Pública debe desplegar sus esfuerzos frente a los estudios y análisis que previa y rigurosamente se deben agotar para determinar con la mayor certeza, el qué, el cómo y el con quién del proceso contractual que se pretende celebrar ${ }^{77}$.

Es con motivo del principio de planeación, que la Administración Pública debe proceder a ejecutar un sinnúmero de acciones, tendientes ellas, a que la futura contratación se desarrolle de conformidad con todas y cada una de las exigencias legales y reglamentarias respectivas; a fin de evitar improvisaciones y de lograr la finalidad última de todo proceso contractual: la satisfacción de los intereses generales y el cumplimiento de los cometidos estatales. En tales actuaciones se pueden enlistar las siguientes: (i) seleccionar objetivamente al contratista que ha de ejecutar una obra, o proveer un bien o un servicio ${ }^{78}$; (ii) constituir los compromisos presupuestales que sean necesarios para cubrir el pago de las obligaciones derivadas del contrato ${ }^{79}$; (iii) incluir en el presupuesto anual una apropiación global destinada al cubrimiento de los costos imprevistos que se ocasionen por el retardo en los pagos y por la revisión de precios cuando las condiciones iniciales del contrato sean alteradas $^{80}$; (iv) realizar un riguroso análisis acerca de la conveniencia o no del objeto a contratar ${ }^{81}$; (v) hacer, durante la etapa de planeación, el análisis para conocer el sector relativo al objeto del proceso de contratación, dejando constancia de todo ello en los documentos del proceso ${ }^{82}$; (vi) obtener con antelación las autorizaciones, permisos y licencias requeridas para la ejecución del contrato a celebrar ${ }^{83}$; (viii) especificar los términos que han de plasmarse en la minuta del contrato, para lo cual se deberán establecer con absoluta claridad las obligaciones a cargo del contratista y de la entidad contratante ${ }^{84}$; (ix) definir los términos en que se ejercerá la supervisión y/o interventoría del contrato ${ }^{85}$; $(\mathrm{x})$ elaborar el análisis y la matriz de riesgos previsibles asociados al contrato a celebrar, incluyendo la estimación, tipificación y asignación respectivas ${ }^{86}$; (xi) establecer claramente las garantías que la entidad pretende exigir en el proceso contractual ${ }^{87}$ y, (xii) publicar

\footnotetext{
${ }^{76}$ Ley N¹4, de 2011. Artículo 84.

${ }^{77}$ RODRÍGUEZ (2013).

${ }^{78}$ Ley $\mathrm{N}^{\circ} 80$, de 1993. Artículo 25. Numeral 12.

${ }^{79}$ Ley $\mathrm{N}^{\circ} 80$, de 1993. Artículo 25. Numerales 6 y 13.

${ }^{80}$ Ley N80, de 1993. Artículo 25. Numeral 14.

${ }^{81}$ Ley N80, de 1993. Artículo 25. Numeral 7.

82 Decreto $N^{\circ} 1082$, de 2015. Artículo. 2.2.1.1.6.1.

${ }^{83}$ Ley N80, de 1993. Artículo 25. Numeral 7; Decreto N¹082, de 2015. Artículo 2.2.1.1.2.1.1. Numeral 2.

${ }^{84}$ Decreto $\mathrm{N}^{\circ} 1082$, de 2015. Artículo 2.2.1.1.2.1.3. Numeral 11.

${ }^{85}$ Decreto $N^{\circ} 1082$, de 2015. Artículo 2.2.1.1.2.1.3. Numeral 12.

${ }^{86}$ Ley N¹150, de 2007. Artículo 4; Decreto $N^{\circ} 1082$, de 2015. Artículo 2.2.1.1.2.1.1. Numeral 8.

${ }^{87}$ Ley N80, de 1993. Artículo 25. Numeral 19. Subrogado por el artículo 7 de la ley 1150 de 2007.
} 
oportunamente en el Sistema Electrónico para la Contratación Pública - SECOP, dentro de los tres (3) días siguientes a su expedición, el aviso de convocatoria o invitación, el proyecto de pliegos de condiciones, los estudios previos, análisis del sector, y los demás documentos y actos administrativos del proceso de contratación ${ }^{88}$.

La aplicación del principio de planeación parte desde la elaboración misma del Plan Anual de Adquisiciones, como instrumento de planeación contractual que las entidades estatales deben diligenciar, publicar y actualizar oportunamente, es preciso señalar que con la expedición del Decreto 1082 del 26 de mayo de 2015, todo lo relativo a la planeación del proceso de contratación, se encuentra regulado en la Parte 2 (Reglamentaciones), Título 1 (Contratación Estatal), Capítulo 1 (Sistema de compras y contratación pública), Sección 2 (Estructura y documentos del proceso de contratación), Subsección 1 (Planeación), desde el artículo 2.2.1.1.2.1.1, hasta el artículo 2.2.1.1.2.1.5, en donde se hace alusión a los estudios y documentos previos como soporte básico para la elaboración del proyecto de pliegos, del pliego de condiciones y del contrato, lo cual incluye obviamente el deber de realizar el análisis del sector relativo al objeto del proceso de contratación, es decir, lo que se conoce como análisis del sector económico, de lo cual se deberá dejar evidencia en los documentos del proceso contractual ${ }^{89}$.

Esta sección del Decreto 1082 de 2015, se refiere además a la información que se debe plasmar en el aviso de convocatoria para efectos de la participación en un proceso de contratación, información que se entiende como adicional a la establecida específicamente para cada modalidad de selección ${ }^{90}$; los ítems que se deben incluir en los pliegos de condiciones, incluyendo el cronograma y la minuta del contrato; así como el término para que los interesados hagan observaciones al proyecto de pliegos de condiciones; $y$, los requerimientos necesarios que se deben contemplar en el acto administrativo de apertura del proceso de selección ${ }^{91}$.

Desde la etapa precontractual el principio de planeación es el bastión fundamental para la celebración de los contratos estatales. El Consejo de Estado sostiene que su desconocimiento puede conducir, en determinados eventos, a la nulidad absoluta del contrato estatal por objeto ilícito, cuando por ejemplo: (i) desde el momento de celebrarse el negocio jurídico se podía evidenciar que el objeto contractual no podría ejecutarse; (ii) que su ejecución dependería de circunstancias indefinidas e inciertas por requerir decisiones de terceros y, (iii) en aquellas situaciones que desde la celebración del contrato ponen en evidencia que los tiempos de ejecución pactados no podrán cumplirse, por lo que inevitablemente habrá de sobrevenir el consiguiente detrimento patrimonial para la entidad ${ }^{92}$.

No toda deficiencia en la planeación del contrato estatal conduce necesariamente a la nulidad del mismo por ilicitud de su objeto, tal y como lo da a entender la Sala de lo Contencioso Administrativo, Sección Tercera del Consejo de Estado en providencia del 20 de octubre de 2014, expediente $24809^{93}$. Pero no solo resulta reprochable la inobservancia del principio de planeación por parte de las entidades estatales, habida cuenta que en la contratación administrativa también se hacen partícipes los colaboradores privados como contratistas del Estado, quienes de conformidad con el inciso segundo del artículo $3^{\circ}$ de la Ley 80 de 1993, al celebrar y ejecutar contratos con dichas entidades, no solo colaboran con ellas en el logro de sus fines, sino que ello

\footnotetext{
${ }^{88}$ Ley No 1150, de 2007. Artículo 8; Decreto No 1082, de 2015. Artículo 2.2.1.1.1.7.1.

${ }^{89}$ Decreto $\mathrm{N}^{\circ} 1082$, de 2015. Artículo. 2.2.1.1.1.6.1.

${ }^{90}$ Decreto $N^{\circ} 1082$, de 2015. Artículo. 2.2.1.1.2.1.2.

${ }^{91}$ BETANCUR (2015).

${ }^{92}$ Consejo de Estado, Expediente $\mathrm{N}^{\circ} 51489$, de 10 de diciembre de 2015.

${ }^{93}$ Consejo de Estado, Expediente $N^{\circ} 24809$, de 20 de octubre de 2014.
} 
comporta una función social que como tal implica obligaciones. Esta afirmación se corrobora en el numeral segundo del artículo $4^{\circ}$ de la misma ley, toda vez que, es deber del contratista colaborar con las entidades contratantes en lo que sea necesario para que el objeto contratado se cumpla, para lo cual deberán obrar con lealtad y buena fe en las distintas etapas del proceso contractual, lo que conlleva también la observancia del principio de planeación.

El Consejo de Estado ha expresado que los particulares, sobre todo aquellos que participan como contratistas del Estado, no solo tienen la obligación de poner de presente las evidentes deficiencias de planeación que sean advertidas, en orden a que las mismas puedan ser subsanadas oportunamente, sino que también se deben abstener de suscribir los contratos en los cuales se evidencien faltas en su planeación que impidan la cabal ejecución o cumplimiento del objeto contractual $^{94}$.

Lo anterior es de trascendental relevancia de cara a futuras reclamaciones, así lo ha dado a entender la Sección Tercera del Consejo de Estado en sentencia del 28 de enero de 2016, expediente 34.454; de tal suerte que, en aquellas situaciones en que la desatención del contratista a las cargas y exigencias que impone el principio de planeación, y la omisión a la diligencia y rigor requeridos para la estructuración de su oferta, traiga como consecuencia la derivación de consecuencias económicas desfavorables para el mismo, dicho contratista no podrá invocar el rompimiento del equilibrio económico del contrato aduciendo, bien sea la teoría de la imprevisión, o la falta de planeación de la entidad, y mucho menos para soportar pretensiones resarcitorias a su favor; ello resulta comprensible, en la medida en que el contratista, como experto y conocedor de su marco de actividades, debió haber previsto las consecuencias negativas de la falta de rigor y seriedad en la planificación de su oferta de obras, bienes y servicios a la entidad estatal ${ }^{95}$.

En síntesis, como lo advierte la máxima autoridad en materia de lo contencioso administrativo, cuando se pretenda alegar la nulidad absoluta del contrato estatal por inobservancia del principio de planeación, e invocando el objeto ilícito como causal prevista en el derecho común, inexorablemente se deberá probar cualquiera de los eventos ya mencionados anteriormente, pues, de lo contrario, la magnitud de la falla de planeación no será suficiente para que se configure un objeto ilícito que dé lugar a la declaratoria de nulidad absoluta del contrato ${ }^{96}$.

Por mandato constitucional ${ }^{97}$, el Consejo de Estado es un órgano de naturaleza judicial que representa la máxima autoridad de lo contencioso administrativo ${ }^{98}$. Comparte con las demás entidades públicas el deber superior de asegurar la supremacía y vigencia de las disposiciones constitucionales. En atención a la jurisdicción especializada que la Constitución le señala, se ocupa revisar, como órgano de cierre, aquellos casos donde el Estado sea parte. Su estructura orgánica faculta a una de sus Secciones, o según el caso a la Sala plena, para dirimir los conflictos de interpretación, compresión o corrección de la normativa en el desarrollo de la contratación pública. Es por ello que como expresión del contenido de sus pronunciamientos, presentamos un esquema de la naturaleza, contenido y estructura del principio de planeación que dicha Corporación ha establecido: (i) la buena fe exenta de culpa consagrada en el artículo 863 del Código de Comercio es desarrollo "del principio general de planeación que debe informar a toda actividad contractual del Estado"99; (ii) un "debido proceso de planeación del negocio es garantía de una adecuada y seria

\footnotetext{
${ }^{94}$ Consejo de Estado, Expediente $\mathrm{N}^{\circ} 51489$, de 10 de diciembre de 2015.

${ }^{95}$ Consejo de Estado, Expediente $\mathrm{N}^{\circ} 49.847$, de 27 de enero de 2016.

${ }^{96}$ Consejo de Estado, Expediente $N^{\circ} 51489$, de 10 de diciembre de 2015.

${ }^{97}$ Constitución Política de Colombia, de 1991. Título VIII. De la Rama Judicial Capítulo III. De la Jurisdicción Contencioso administrativa, Artículo 237.

${ }^{98}$ RESTREPO (2018), pp. 163-166.

${ }^{99}$ Consejo de Estado, Expediente $N^{\circ} 57.421$, de 29 de enero de 2018.
} 
inversión en los proyectos públicos"100; (iii) el deber de información emerge, no solo de los principios jurídicos, sino también de aquellos que orientan la contratación estatal, especialmente los de planeación y economía ${ }^{101}$; (iv) la planeación es un deber que obliga a las administraciones públicas a que los negocios sean debidamente diseñados, pensados, conformes con las necesidades y prioridades de interés público, sin que prime la improvisación ${ }^{102}$; (v) el principio de planeación está ligado al criterio de oportunidad que es trascendente para la prestación inmediata y eficiente del servicio público, para precisar el precio real de lo que será objeto del contrato "de tal suerte que pueda tener un marco de referencia que le permita evaluar objetivamente las propuestas que se presenten durante el respectivo proceso de escogencia del contratista" ${ }^{103}$; igualmente para que los recursos públicos sean aprovechados eficientemente, y para que se cumpla con el deber imperativo de la selección objetiva en la escogencia de la oferta más favorable para la entidad; (vi) el deber de planeación también es exigible a los sujetos privados que participan en procesos o estructuración de negocios con el Estado y que los ejecutan, tal y como se desprende de lo consagrado en el inciso 20 del artículo 3 de la Ley 80 de 1993 ${ }^{104}$; (vii) la trasgresión del principio de planeación tiene como consecuencia de orden legal que "conduce a la nulidad absoluta del contrato por ilicitud del objeto porque de acuerdo con el derecho común esto es lo que se configura en todo acto que contraviene al derecho público"105; (viii) las deficiencias de planeación del contrato que violentan el orden jurídico son aquellas que desde su celebración evidencian que el objeto no podrá ejecutarse, o que su ejecución va a depender de situaciones indefinidas o inciertas por necesitar de decisiones de terceros, o que los tiempos de ejecución acordados no podrán cumplirse, sobreviniendo el consiguiente detrimento patrimonial para la entidad contratante debido a los sobrecostos en que habrá de incurrirse por el retardo ${ }^{106}$; (ix) la cláusula de prórroga automática de un contrato de arrendamiento estatal se aparta del deber de planeación ${ }^{107} y,(x)$ la falta de planeación del negocio jurídico deviene en la responsabilidad de los servidores públicos y de las entidades estatales, de acuerdo con lo previsto en el artículo 26 de la Ley 80 de 1993.

\section{Principio de planeación y supuestos fácticos}

Supuesto 1: la Sección Tercera del Consejo de Estado en Fallo del 20 de octubre de 2014, Expediente 24809, al negar las pretensiones de la demanda, tuvo como argumento central la violación al principio de planeación; se trata de la controversia contractual interpuesta por la sociedad CONCONCRETO S.A en contra del Instituto Nacional de Vías-INVIAS, en virtud del contrato N 352 celebrado el 27 de junio de 1994, para la construcción de la solución vial PereiraDosquebradas Grupo III. Argumentó el alto Tribunal, que no se puede negar la existencia de un objeto ilícito "cuando un contrato se celebra en circunstancias contrarias a las ordenadas imperativamente por la ley, tal y como sería el caso de no observar el principio de planeación en la celebración de los contratos estatales" ${ }^{108}$. Una adecuada planeación es la vía correcta para evitar las múltiples dificultades que se pueden presentar en las relaciones contractuales del Estado; y dado

\footnotetext{
100 Consejo de Estado, Expediente N57.421, de 29 de enero de 2018.

${ }^{101}$ Consejo de Estado, Expediente N57.421, de 29 de enero de 2018.

102 Consejo de Estado, Expediente N57.421, de 29 de enero de 2018.

103 Consejo de Estado, Expediente N57.421, de 29 de enero de 2018.

${ }^{104}$ Consejo de Estado, Expediente N57.421, de 29 de enero de 2018.

105 Consejo de Estado, Expediente $N^{\circ} 57.421$, de 29 de enero de 2018.

${ }^{106}$ Consejo de Estado, Expediente $N^{\circ} 57.421$, de 29 de enero de 2018.

${ }^{107}$ Consejo de Estado, Expediente $N^{\circ} 57.421$, de 29 de enero de 2018.

${ }^{108}$ Consejo de Estado, Expediente $N^{\circ} 24809$, de 20 de octubre de 2014.
} 
que dicho principio es una exigencia perentoria del ordenamiento jurídico, se entiende razonablemente que su violación es constitutiva de un objeto ilícito que bien podría ser causa de nulidad absoluta del respectivo negocio jurídico ${ }^{109}$.

Supuesto 2: Fallo del Consejo de Estado del 28 de mayo de 2012, Expediente 21.489, en el cual la Corporación al revocar una sentencia proferida por el Tribunal Administrativo de Arauca, declaró la nulidad absoluta de varios contratos de obra pública celebrados entre el municipio de Arauca y un sujeto particular, sin dar lugar a restituciones mutuas y compulsando copias ante la Procuraduría General de la Nación y la Fiscalía General de la Nación para efectos de las investigaciones disciplinarias y penales de su competencia. Adujo el Alto Tribunal en su argumentación, que en el caso subexamine se vulneró el principio de planeación, toda vez que en el expediente administrativo de los contratos no se observó que se hubiesen adelantado los estudios de conveniencia y oportunidad, técnicos, jurídicos y financieros que soportaran la necesidad y las especificaciones de la contratación, así como los planos, diseños y proyectos requeridos, en contravención a lo dispuesto en los artículos 24 y 25 de la Ley 80 de 1993, coligiendo que el municipio no realizó estudio previo alguno para establecer la necesidad de la obra y la conveniencia de la contratación, ni definió las condiciones ni el procedimiento de evaluación, requisitos necesarios para la validez del contrato que resulte ser suscrito como resultado de cualquier proceso de selección. Esto, aunado a que las disponibilidades presupuestales fueron expedidas con posterioridad a la apertura y adelantamiento del trámite de los procesos de contratación, todo ello en desconocimiento de lo establecido en el numeral 6 del artículo 25 de la Ley 80 de 1993, es decir, del principio de planeación (Consejo de Estado, 2014a).

Supuesto 3: la Sección Tercera del Consejo de Estado al resolver un recurso de apelación de una demanda interpuesta por una empresa particular de ingenieros en contra del Departamento de Boyacá, Colombia, a través del medio de control de controversias contractuales, en un litigio en el cual se pretendía el restablecimiento de un supuesto desequilibrio contractual, la Corporación exoneró de responsabilidad al Estado y negó el petitum de la demanda, precisamente porque no se acreditaron las circunstancias generadoras de dicho desequilibrio que pudieran dar lugar al restablecimiento del equilibrio económico del contrato. Como soporte argumentativo de tal decisión, expresó al alto Tribunal:

Así, por ejemplo, si una entidad estatal celebra un contrato para ejecutar una obra pública en un corto lapso de tiempo (habida cuenta de la magnitud y complejidad de la obra) y al momento de la celebración del negocio ni siquiera ha entrado en negociaciones con los propietarios de los terrenos sobre los cuales la obra se va a hacer, ni ha adelantado diligencia alguna para su adquisición, o solo se ha adquirido una parte de ellos, es obvio que en ese contrato se faltó al principio de planeación de tal manera que desde ese instante ya es evidente que el objeto contractual no podía ejecutarse en el tiempo acordado y por consiguiente infringen la ley no solo la entidad estatal sino también el contratista al celebrar un contrato con serias fallas de planeación puesto que todo indica que el objeto contractual no podrá realizarse o será muy difícil realizarlo en el tiempo prefijado (Consejo de Estado, 2017).

\footnotetext{
${ }^{109}$ Consejo de Estado, Expediente N²4809, de 20 de octubre de 2014.
} 


\section{Conclusiones}

La Constitución Política de Colombia, mediante sus principios, valores y derechos fundamentales, concebidos a la luz de los presupuestos hermenéuticos que lidera la Corte Constitucional ha representado una comprensión del derecho más allá de la estricta visión legalista y exegética que orientó la forma de concebir el sistema normativo por más de dos siglos. El cambio de paradigma obedece a una nueva manera de concebir las normas en un sentido más amplio de la ley y soportado en el resorte constitucional. De tal forma que principios y valores, en tanto expresión de disposiciones constitucionales, gozan en sí mismos, de fuerza jurídica vinculante para fundar la decisión de un servidor público y para explicar el contenido y alcance del sistema normativo sobre un caso específico.

En este trabajo, nos hemos ocupado de analizar la naturaleza y estructura del principio de planeación y mostrar de qué manera incide en el ámbito de la contratación pública. Hemos mostrado de qué manera los principios surten y nutren todo el marco de interpretación normativa de la contratación. Afirmamos la necesaria inter-relación e interdependencia entre todos y cada uno de los principios generales inmersos en la contratación pública.

Es dable concluir que, no obstante contar con un estatuto de principios en materia de compras públicas, no es menos cierto que del mismo cuerpo normativo no se colige la existencia de un balance adecuado entre tales principios, habida cuenta que, aún en el presente, ellos siguen siendo soslayados por el exceso de reglamentaciones y de trámites innecesarios, que a su vez suelen ser bastante dispendiosos y representan costos adicionales para las entidades estatales, dando al traste con los principios de economía, transparencia, celeridad, eficacia y eficiencia que deben distinguir toda clase de actuaciones y procesos destinados a satisfacer las necesidades colectivas a través del mecanismo de la contratación administrativa.

El principio de planeación se convierte en un postulado fundante e integrador que irradia absolutamente y despliega sus efectos en todo el iter contractual, que actúa de manera envolvente en interdependencia con todos los demás principios, y que es sin duda, el eje fundamental sobre el cual se desarrolla el proceso de ejecución de obras, y la adquisición de bienes y servicios por parte de las entidades estatales.

\section{BIBLIOGRAFÍA CITADA}

ALEXY, ROBERT (1994): El concepto y la validez del derecho (Barcelona, Gedisa).

ÁLVAREZ, FRANCISCO (2010): Sobre el principio de legalidad (Valencia, Tirant Lo Blanch).

ARISTÓTELES (2008): Política (Madrid, Gredos).

BASTIDA, XACOBE (2001): El silencio del emperador. Un ensayo sobre la unidad del ordenamiento jurídico (Bogotá, Unibiblos).

BeRnAL, CARLOS (2006): "La Corte Constitucional dentro del Estado social de derecho colombiano, un órgano legitimador del derecho dentro de la sociedad", en: Sanín, Ricardo (Ed.), Justicia Constitucional. El rol de la Corte Constitucional en el Estado contemporáneo (Bogotá, Legis), pp. 245-257. 
BETANCUR, GUILLERMO (2015): Aspectos Generales de la Contratación Estatal, en: Hoyos García, J. F., La Contratación Estatal. Una visión desde el Derecho Privado hacia lo público (Medellín, Diké).

CAPELLA, JUAN RAMÓN (2008): Fruta prohibida. Una aproximación histórico-teorética al estudio del derecho y del estado (Madrid, Trotta).

DWORKIN, RONALD (1995): Los derechos en serio (Barcelona, Ariel).

ESTRADA, SERGIO (2007): Los principios jurídicos y el bloque de constitucionalidad (Medellín, Sello editorial Universidad de Medellín).

FANDIÑO, JORGE ELIÉCER (2014): La contratación estatal (Bogotá, Leyer).

FERRAJOLI, LUIGI (2014): La democracia a través de los derechos. El constitucionalismo garantista como modelo teórico y como proyecto político (Madrid, Trotta).

GARCíA ENTERRÍA, EDUARDO (2001): La constitución como norma y el tribunal constitucional (Madrid, Civitas).

KELSEN, HANS (2009): Teoría pura del derecho (México, Porrúa).

LEMAITRE, JULIETA (2016): "El movimiento estudiantil de 1989 y la séptima papeleta", en: CEP Banco de la República, De toda la gente: 25 años de la Asamblea Nacional Constituyente (Bogotá, Biblioteca Luis Ángel Arango), pp. 55-58.

LONDOÑO, MABEL (2015): “Participación ciudadana: algo más que elegir y ser elegido. Un estudio desde el proceso constituyente de 1991", en: Bocanument, M.; Rojas, M. y Restrepo, O. (Eds.), Participación ciudadana en el proceso constituyente de 1991 (Medellín, Sello editorial de la Universidad de Medellín y Fondo editorial Corporación Universitaria Remington), pp. 27-90.

LÓPEZ, DIEGO EDUARDO (2006): El derecho de los jueces (Bogotá, Legis).

(2008): La letra y el espíritu de la ley (Bogotá, Temis).

MATALLANA, ERNESTO (2015): Manual de contratación de la administración pública (Bogotá, Universidad Externado de Colombia).

MONTESQUIEU (2007): Del espíritu de las leyes (Madrid, Tecnos).

OLANO, HERNÁN ALEJANDRO (2007): Constitucionalismo histórico. Historia de Colombia a partir de sus constituciones y reformas (Bogotá, Ediciones doctrina y ley).

PALACIO, JUAN ÁNGEL (2014): La contratación de las entidades estatales, 7ạ edición (Medellín, Jurídica Sánchez).

PAREJO, LUCIANO (1998): Manual de derecho administrativo (Barcelona, Ariel). 
RADBRUCH, GUSTAV (2010): Introducción a la filosofía del derecho (México, FCE).

RAWLS, JOHN (2003): Liberalismo político (Barcelona, Crítica).

RESTREPO, JOHN FERNANDO (2013): “El poder constituyente como institución que juridifica el proceso político constituyente de 1990”, en: Ratio luris (Vol. 8, № 17), pp. 47-70.

(2018): Estructura constitucional del estado colombiano, 2ạ edición (Medellín, Sello editorial Universidad de Medellín).

RICO, LUIS ALONSO (2013): Teoría general y práctica de la contratación estatal (Bogotá, Leyer).

RODRÍGUEZ, MAURICIO (2013): Los contratos estatales en Colombia (Medellín, Jurídica Sánchez).

SóFOCLES (2014): Antígona (Madrid, Gredos).

\section{JURISPRUDENCIA CITADA}

SENTENCIA C-508 DE 3 DE JULIO DE 2002. Corte Constitucional de Colombia, M.P. Alfredo Beltrán Sierra.

SENTENCIA T-518A DE 16 DE FEBRERO DE 2011. Corte Constitucional de Colombia, M.P. Mauricio González Cuervo.

SENTENCIA C-300 DE 25 DE ABRIL DE 2012. Corte Constitucional de Colombia, M.P. Jorge Ignacio Pretel Chaljub.

SENTENCIA DEL 28 DE MAYO DE 2012. Expediente 21489, Sección Tercera, Sala Plena de lo Contencioso Administrativo, Consejo de Estado de Colombia, C.P. Ruth Stella Correa Palacio.

SENTENCIA DEL 20 DE OCTUBRE DE 2014. Expediente 24809, Sección Tercera, Sala Plena de lo Contencioso Administrativo, Consejo de Estado de Colombia, C.P. Jaime Orlando Santofimio Gamboa.

SENTENCIA C-492 DE 5 DE AGOSTO DE 2015. Corte Constitucional de Colombia, M.P. María Victoria Calle.

SENTENCIA DEL 10 DE DICIEMBRE DE 2015. Expediente 51489, Sección Tercera, Sala Plena de lo Contencioso Administrativo, Consejo de Estado de Colombia, C.P. Jaime Orlando Santofimio Gamboa.

SENTENCIA DEL 23 DE OCTUBRE DE 2017. Expediente 55.855, Sección Tercera, Sala de lo Contencioso Administrativo, Consejo de Estado, C P. Jaime Orlando Santofimio Gamboa.

SENTENCIA DEL 25 DE ENERO DE 2018. Expediente 1358-12, Subsección A, Sección Segunda, Sala de lo Contencioso Administrativo, Consejo de Estado de Colombia, C.P. Gabril Valbuena Hernández. 


\section{NORMAS JURÍDICAS CITADAS}

CONSTITUCIÓn POLITICA DE COLOMBIA. Gaceta Consticional No. 116, 20 de julio de 1991.

DECRETO 1082, por medio del cual se expide el Decreto Único Reglamentario del Sector Administrativo de Planeación Nacional. Diario Oficial No. 49.523, 26 de mayo de 2015.

LEY 678, por medio de la cual se reglamenta la determinacion de responsabilidad patrimonial de los agentes del Estado a travez del ejercicio de la acción de repetición o de llamamiento en garantía con fines de repeticion. Diario Oficial No. 44.509, 4 de agosto de 2001.

LEY 80, por la cual se expide el estatuto general de contratación de la administración pública. Diario Oficial No. 41.094, 28 de octubre de 1993.

LEY 599, por la cual se expide el código penal. Diario Oficial No. 44.097, 24 de julio de 2000.

LEY 734, por la cual se expide el código disciplinario único. Diario Oficial No. 44.708, 13 de febrero de 2002.

LEY 1150, por medio de la cual se introducen medidas para la eficiencia y la transparencia en la Ley 80 de 1993 y se dictan otras disposiciones generales sobre la contratación con Recursos Públicos. Diario Oficial No. 46.691, 16 de julio de 2007.

LEY 1474, por la cual se dictan normas orientadas a fortalecer los mecanismos de prevención, investigación y sanción de actos de corrupción y la efectividad del control de la gestión pública. Diario Oficial Nro. 48.128, 12 de julio de 2011.

LEY 1437, por la cual se expide el Código de Procedimiento Administrativo y de lo Contencioso Administrativo. Diario Oficial No. 47.956, 18 de enero de 2011.

LEY 1882, por la cual se adicionan, modifican y dictan disposiciones orientadas a fortalecer la contratación pública en Colombia, la ley de infraestructura y se dictan otras disposiciones. Diario Oficial No. 50.477, 15 de enero de 2018. 